\title{
Custos de Agência e Estrutura de Controle em Empresas Petrolíferas
}

\author{
Agency Costs and Ownership Structure in Oil Industry
}

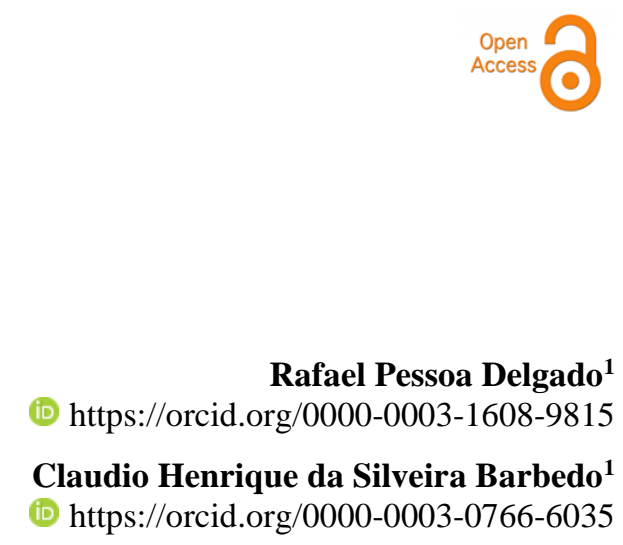

Instituto Brasileiro de Mercado de Capitais, Faculdade de Economia, Rio de Janeiro, RJ, Brasil ${ }^{1}$

Artigo recebido em 20.05.2018. Última versão recebida em 13.12.2018. Aprovado em 07.02.2019. Editor-chefe: Prof. Wesley Mendes-Da-Silva.

\# de revisores convidados até a decisão

\begin{tabular}{lllllllll} 
& 1 & 2 & 3 & 4 & 5 & 6 & 7 & 8 \\
\hline $1^{\mathrm{a}}$ rodada & $\stackrel{D}{0}$ & 2 & & & & & & \\
\hline $2^{\mathrm{a}}$ rodada & 2 & & & & & & & \\
\hline
\end{tabular}




\title{
Resumo
}

Este estudo se propõe a analisar a influência da participação estatal no controle de empresas petrolíferas listadas em bolsas americanas sobre os seus custos de agência, levando em conta características destas companhias. Os resultados indicam que empresas com participação estatal tendem a apresentar maiores custos de agência que seus pares privados quando consideramos a eficiência no uso dos ativos. Utilizando um índice de gastos discricionários os coeficientes sugerem a mesma conclusão, embora não sejam estatisticamente significantes. Adicionalmente, o tamanho das companhias e o seu grau de alavancagem se mostraram fatores relevantes.

Palavras-chave: custos de agência; governança; governo; estrutura de propriedade; petróleo.

\begin{abstract}
This work focuses on analyzing the influence of government ownership of oil companies listed on US stock exchanges on its agency costs, taking into account characteristics of such companies that may interfere on this relationship. Results indicate that companies on which governments hold a stake tend to present higher agency costs than its private peers when we consider asset utilization efficiency. Measuring it by a discretionary expenses index, the coefficients suggest the same conclusion, although they are not statistically significant. In addition, companies' size and leverage were found to be relevant factors.
\end{abstract}

Keywords: agency costs; corporate governance; government; ownership structure; oil.

JEL Code: L6, D23, G32. 


\section{Introdução}

Os custos de agência têm origem nos conflitos de interesse entre principais e agentes e podem ser vistos como a soma dos custos de monitoramento, de imposição de restrições (bonding) aos agentes e de perdas residuais incorridas pelos principais, face à impossibilidade prática de garantir que todas as decisões tomadas pelos agentes maximizem o seu ganho (Jensen \& Meckling, 1976).

A indústria de petróleo possui algumas características interessantes para o estudo dos custos de agência. Jensen (1986) indica que companhias petrolíferas que apresentam elevado fluxo de caixa livre e baixo endividamento tendem a maiores custos de agência. Byrd (2010) encontra resultados similares que sugerem que a dívida nas empresas de petróleo diminui os custos de agência. Jacobs (1986) sugere que em empresas com pouca influência de capital de terceiros, gerentes da indústria petrolífera costumam continuar com explorações custosas de reservas de óleo ainda que em momentos de declínio dos preços.

Além disso, indústrias de petróleo são mais suscetíveis a controles estatais, principalmente em mercados emergentes, por conta de incertezas jurídico-institucionais e do próprio risco do investimento. A literatura sobre participação em empresas pelo estado é associada com ineficiência e baixa performance (Shleifer \& Vishny, 1997), mas também com melhores decisões de financiamento e investimento (Boubakri, Ghoul, \& Guedhami, 2018) e um menor custo de financiamento em momentos de crise financeira ou para empresas com mais possibilidade de incertezas (Borisova, Fotak, Holland, \& Megginsonl, 2015).

A literatura financeira ainda apresenta pouco aprofundamento sobre a consequência do controle estatal sobre empresas de petróleo. Gilje e Taillard (2016) exploram uma amostra de produtores de óleo e gás no mercado americano e demonstram diferenças no comportamento de investimento de empresas públicas. O objetivo deste estudo é avaliar, dentro de um mercado específico, a seguinte questão: $\mathrm{O}$ custo de agência nas empresas de petróleo estatais listadas em Bolsas americanas é maior do que nos seus pares sem o controle estatal? O resultado desta pesquisa pode ser particularmente importante para investidores e gestores de carteira, considerando que o setor de petróleo é importante para a construção de uma carteira diversificada.

A elevação de preços de petróleo registrada no início dos anos 2000 perdurou até 2014, excetuando-se um breve período após a crise dos subprimes em 2008, o que elevou substancialmente o fluxo de caixa livre das empresas e manteve o endividamento, em geral, baixo. Além disso, o petróleo é considerado um bem estratégico, fomentando interferência governamental no negócio e o surgimento de companhias total ou parcialmente controladas por governos. Tais características sugerem que a indústria petrolífera é mais suscetível a situações de risco moral e excesso de investimento que outros segmentos. Adicionalmente, empresas petrolíferas ainda carregam uma carga ideológica de discussão sobre a permanência da atuação estatal neste segmento. Shleifer e Vishny (1994), por exemplo, propuseram um modelo de barganha entre políticos e gestores que indica que os governos controlam empresas com objetivos mais políticos que sociais, provendo empregos, subsídios e outros benefícios para seus apoiadores.

Morck, Shleifer e Vishny (1988) apresentam as bases para um estudo empírico sobre a teoria da estrutura de propriedade de Jensen e Meckling (1976), verificando a relação entre o Q de Tobin e o percentual de ações em posse dos conselheiros de administração. Ang, Cole e Lin (2000) e Singh e Davidson (2003) desenvolveram variáveis para mensurar os custos de agência em empresas listadas nos Estados Unidos. Os autores utilizaram como variáveis dependentes a razão vendas/ativos totais, um indicador de eficiência no uso dos ativos, e as despesas de vendas, gerais e administrativas, medida contábil que contempla, dentre outros, salários de executivos, privilégios e regalias em benefício dos executivos e funcionários.

No Brasil, há uma vasta literatura sobre o desempenho a partir de características da governança e/ou do conselho de administração (Andrade, Salazar, Calegario, \& Silva, 2009; Lima, Oliveira, Cabral, 
Santos, \& Pessoa, 2015; Silveira, Barros, \& Fama, 2003). Entretanto, os trabalhos abrangem somente as companhias listadas, sem identificar especificidades de cada setor econômico.

Este estudo se propõe a investigar se há um maior custo de agência nas empresas de petróleo listadas nos EUA com participação de governos. Para atingir este objetivo, foram avaliados os custos de agência por meio das proxies utilizadas por Singh e Davidson (2003) através de regressões de painel. Paralelamente, as empresas que possuem participação/controle estatal foram comparadas com as demais do setor visando confirmar se aquelas possuem, de fato, maiores custos de agência.

Uma preocupação natural com resultados de regressões de painel é a possibilidade de causalidade reversa. Desta forma, é possível que empresas com maior participação estatal existam em países ou áreas em que o giro do ativo seja menor ou as despesas administrativas sejam maiores. Dessa forma, não é a propriedade estatal que aumentaria os custos de agência. Para considerar essa questão, utilizamos diferentes variáveis de controle e selecionamos empresas a partir de um mercado financeiro específico, sob a suposição de que isso gere uma amostra com características mais homogêneas.

Os resultados sugerem que as empresas listadas com participação estatal possuem maiores custos de agência, especificamente quando o custo de agência é medido por meio do giro do ativo. Utilizando a razão despesas de vendas, gerais e administrativas/vendas anuais, os resultados não foram significantes, embora os coeficientes tenham o sinal correto.

Diferentemente de Singh e Davidson (2003), foram encontradas evidências de que blocos de controle estão associados ao uso mais eficiente dos ativos, o que não ocorreu, no entanto, com a participação de executivos e conselheiros no capital das empresas e nem com o número de conselheiros, visto que não houve relação significativa entre estes e o custo de agência na presente análise.

O restante deste estudo está dividido em 4 seções. A segunda seção traz uma breve revisão da literatura sobre o tema. A seção seguinte apresenta a base de dados utilizada bem como a metodologia aplicada. Os resultados são detalhados na quarta seção e, a seguir, as conclusões.

\section{Revisão de Literatura}

\section{Custos de agência e governança corporativa}

Jensen e Meckling (1976) apresentaram uma teoria de estrutura de propriedade das firmas, tomando por base conceitos da teoria da firma, de agência e de finanças. A teoria então proposta diferencia a estrutura de capital e a estrutura de propriedade, pois traz foco a um problema então pouco discutido: a proporção do capital de uma empresa detido por insiders, que são os gestores e funcionários que possuem parte do capital, e outsiders, que são os sócios que detém parte do capital, mas não estão envolvidos no dia a dia da empresa.

Os autores definiram a relação de agência como um contrato sob o qual o principal contrata o agente, mediante a delegação de algum poder de decisão, para realizar um dado trabalho em seu favor. Assumindo que ambos são maximizadores de utilidade, eles inferem que o agente nem sempre tomará as melhores decisões sob o ponto de vista do contratante. Os custos de agência foram definidos, portanto, como a soma dos gastos em monitoramento por parte do principal, dos custos com incentivos e de eventuais perdas residuais em relação ao ponto ótimo caso o principal tomasse todas as decisões.

Ang et al. (2000) utilizam como referência empresas geridas pelos seus próprios donos como o referencial para custo de agência zero em suas análises (zero agency-cost base case), como sugerido por Jensen e Meckling (1976). Os resultados encontrados indicam que empresas com acionistas externos têm maiores custos de agência e estes aumentam na medida em que a participação dos gestores (insiders) no capital diminui. Além disso, também apontam para um efeito positivo do monitoramento exercido por bancos que emprestam recursos a estas empresas. 
Este último resultado está de acordo com o proposto por Jensen (1986), no qual a emissão de dívida possui um efeito positivo sobre os custos de agência em companhias com gestores externos, pois os compromete com o pagamento de juros e principal futuramente sob a ameaça de falência em caso de descumprimento das obrigações. Este tipo de compromisso firme não é alcançado por meio de dividendos e é capaz de reduzir o dinheiro extra disponível para os gestores gastarem de forma discricionária e ineficiente, como em projetos cuja remuneração é menor que o custo de capital.

Singh e Davidson (2003) encontraram resultados semelhantes em relação ao capital detido por insiders, mas resultados diferentes em relação à alavancagem, indicando que maior endividamento estava associado com menor eficiência no uso dos ativos. Além disso, eles analisaram o efeito da participação de blocos de acionistas no capital, o impacto da composição e do tamanho do conselho de administração. Destes, apenas um board numeroso estava associado, com significância estatística, ao aumento do custo de agência medido pelo giro do ativo.

Sobre blocos de acionistas, alguns estudos anteriores sugerem impactos positivos na governança da empresa. Fama e Jensen (1983) propõem que conselheiros externos à organização auxiliam na tomada de decisão e solução de conflitos, bem como monitoram a performance dos demais gestores, o que teria efeitos positivos sobre os custos de agência. Yermack (1996) encontrou evidências de que o maior número de conselheiros está associado a uma pior performance das empresas, o que indica que a eficiência como monitor das decisões ficaria comprometida. Quanto à existência de blocos de controle, Shleifer e Vishny $(1986,1997)$ analisam formas como os detentores de grandes blocos de ação podem trazer melhorias à gestão das firmas exercendo um papel que não ocorreria quando o controle da empresa é extremamente pulverizado em função de um problema de free-rider ${ }^{1}$. A presença de blockholders, portanto, seria um estímulo ao monitoramento acarretando em menores custos de agência, embora possa gerar problemas quando este grande acionista passa a ter controle total da companhia e usa este poder para expropriar recursos dos minoritários.

Mcknight e Weir (2009) examinam o impacto de variáveis de governança e estrutura de controle sobre o custo de agência medido em empresas do Reino Unido listadas. Utilizando-se de uma alteração regulatória sobre a formatação do conselho de administração naquele país, eles sugerem que não há uma formatação ideal, e sim um conjunto de configurações de governança que maximizam valor. De forma mais específica, quando avaliado sob a ótica do giro do ativo, eles encontraram evidências de que a participação de conselheiros no capital reduz o custo de agência, o que pode ser considerado análogo à participação de insiders, ocorrendo o mesmo com o aumento da alavancagem. Por outro lado, não houve indicação de que a independência do board ou a presença de detentores de blocos de ações esteja associada com menores custos de agência. Owusu e Weir (2018) também replicam este mesmo estudo em Gana e encontram resultados similares. Rossi, Barth e Cebula (2018) afirmam que dívida e o tipo de acionista são os fatores determinantes para mitigar ou exacerbar os custos de agente para companhias italianas listadas em bolsa. Elkelish (2018) investiga o relacionamento entre governança e custo de agência em 27 países. $\mathrm{O}$ autor verifica que o custo dos agentes aumenta o risco de governança em todos os países, com destaque para as empresas não financeiras.

Bernardino, Peixoto e Nascimento (2015) verificam que a boa governança reduz o problema de agência e aumenta o valor da firma, a partir de uma amostra de empresas do setor elétrico da Bolsa brasileira. Almeida, Klotzle e Pinto (2013) apontam que o tamanho e a independência do conselho de administração têm relação positiva e significante com o desempenho das empresas.

\section{Participação estatal}

Há vários argumentos que usualmente suportam a existência de firmas de propriedade estatal, como melhor atender ao interesse público, seja maximizando os ganhos sociais ou provendo um serviço que supostamente não seria feito pela iniciativa privada, ou seja, corrigindo falhas de mercado. Além disso, muitas vezes o aspecto estratégico de determinada atividade é considerado como relevante para que o estado tenha participação em uma companhia. Um resumo não exaustivo das correntes de pensamento sobre este tema desde o século passado pode ser encontrado em Shleifer (1998). 
Diversos estudos empíricos, no entanto, indicam que empresas estatais são ineficientes decorrente da interferência política. Shleifer e Vishny (1994) analisam problemas de corrupção e ineficiência decorrentes de uma relação entre políticos e empresas, sejam elas públicas ou privadas, quando políticos tentam influenciá-las para que busquem objetivos políticos ao invés de empresariais. Nestes casos, políticos proveem empregos e subsídios aos seus apoiadores e em troca recebem votos, contribuições políticas ou puramente suborno.

Essencialmente os autores concluem que a privatização nem sempre solucionará os problemas e, mais que isso, em certas condições pode até aumentar a corrupção. A solução está vinculada a tornar os subsídios estatais limitados e mais custosos aos políticos, o que poderia ocorrer com um Tesouro independente ou por meio de um eleitorado mais vigilante, limitando a sua capacidade de atuar 'em favor' da empresa.

La Porta, Lopez-de-Silanes e Shleifer (2002) analisaram a participação estatal no setor bancário para verificar que países seguiram este modelo e se o resultado foi bem-sucedido em promover o desenvolvimento financeiro e o crescimento econômico. Duas visões embasam esta discussão: a visão desenvolvimentista preconiza que a participação estatal nas instituições financeiras levará a um maior desenvolvimento econômico, aumento da riqueza e da produtividade, enquanto a visão política sugere que o financiamento privado será prejudicado e que os projetos financiados por bancos estatais tenderão a ser mais ineficientes e, portanto, prejudicarão a produtividade. Com dados sobre 92 países, a conclusão é de que a participação estatal em bancos está de fato associada aos países mais pobres, com sistemas financeiros subdesenvolvidos e com grande intervenção estatal na economia em 1970 e que este quadro permanecia em 1995. Além disso, a maior participação do estado no capital dos bancos está associada ao exato oposto da visão desenvolvimentista, ou seja, menor crescimento econômico, desenvolvimento mais lento do sistema financeiro e baixo crescimento da produtividade, favorecendo a visão política sobre a participação do estado não só em bancos, mas nas empresas em geral.

Borisova, Brockman, Salas e Zagorchev (2012) concluem que o controle governamental está associado a uma menor qualidade de governança nas empresas europeias, em sistemas jurídicos menos protetores. Borisova, Fotak, Holland e Megginsonl (2015) verificam um menor custo de financiamento nas empresasa estatais em momentos de crise financeira e em empresas com maior possibilidade de incertezas.

Boubakri, Ghoul e Guedhami (2018) encontram robustas evidências que firmas estatais apresentam valor de mercado maior que empresas não estatais, embora a relação não seja linear. Este efeito é verificado por meio de melhores decisões de financiamento e investimento. Beuselinck, Cao, Deloof e Xia (2017) encontram que, durante a crise financeira de 2008, o controle estatal direto ou indireto garantiu um maior valor para empresas especialmente localizadas em países com melhor proteção ao investidor e com menor grau de corrupção, a partir de uma amostra de empresas europeias. Consistente com a ideia de que empresas estatais estão sujeitas a maior intervencionismo na sua gestão, Chen, Ghoul, Guedhami, Kwok e Nash (2018) demonstram que as empresas com maior participação do governo promovem mais crédito para os seus parceiros comerciais. Por outro lado, Chen, Ghoul, Guedhami e Nash (2018) encontram uma relação positiva entre controle do governo e as disponibilidades de caixa nas empresas. A partir destes estudos, é esperado um relacionamento entre a participação governamental e o valor da empresa.

\section{Dados e Metodologia}

\section{Seleção da amostra}

A base de dados contém 257 empresas listadas em bolsas americanas, produtoras de óleo e gás (subsetores ICB 0533, companhias de exploração \& produção, e ICB 0537, companhias integradas) cujo faturamento é superior a US\$ 100 milhões em 2016. Tendo em vista a hipótese de que uma elevada 
geração de fluxo de caixa livre nas firmas estar vinculada a um maior custo de agência (Jensen, 1986) e as acentuadas quedas nos preços do petróleo ocorridas em 2008 e 2014, que afetaram a capacidade de gerar recursos destas companhias, o período de análise proposto foi de 2007 a 2016 . A escolha pelo mercado americano é justificada pelo fato de que esse mercado tem listado mais de $75 \%$ do faturamento da indústria considerando as maiores empresas do setor. Considerando dados de capitalização de mercado de 35 bolsas do mundo inteiro, as empresas listadas nas bolsas americanas correspondem a $62 \%$ do setor.

Visando a manutenção de uma base de dados consistente, foram selecionadas as empresas que possuíssem no mínimo 50\% das variáveis de interesse válidas no período analisado. Parte das informações foi complementada com uma pesquisa adicional de dados do balanço patrimonial e do demonstrativo de resultados disponibilizados pela consultoria especializada Evaluate Energy. A amostra final totalizou 160 empresas.

As informações sobre o percentual de participação de blockholders e do governo no controle das companhias foram obtidas a partir da base de dados Orbis. A partir das 160 empresas, a Orbis indicou como proprietário final (Global Ultimate Owner) o governo do país de origem da companhia em 28 delas e, nestes casos, uma pesquisa adicional foi feita nos relatórios destas companhias. As fontes de informação foram majoritariamente: Annual Report, 20-F Report, Shareholding Pattern para empresas indianas e websites das empresas.

Tais informações foram tratadas buscando representar da forma mais fidedigna possível a propriedade por parte de um indivíduo ou grupo coeso de acionistas, os quais estariam mais propensos a exercer o controle ativo da companhia, potencialmente reduzindo seus custos de agência. Os tipos de acionistas $\mathrm{D}, \mathrm{L}$ e $\mathrm{Z}^{2}$ foram excluídos, assim como agrupamentos que representam a negociação de American Depositary Receipts (ADR).

\section{Custos de agência}

Os custos de agência em uma empresa não são diretamente observáveis e, por isso, requerem o uso de indicadores como proxy. Este estudo considerou duas medidas para estimar o custo de agência nas empresas, seguindo Singh e Davidson (2003) e Henry (2010), a saber (a) a razão vendas anuais / ativo total $\left(\right.$ Giro $\left._{i, t}\right)$ e (b) despesas de vendas, gerais e administrativas anuais / vendas anuais $\left(D V G \& A_{i, t}\right)$. A notação $i$ representa o ativo e a notação $t$ representa o período.

A primeira medida representa o giro do ativo e é uma forma de medir quão eficiente cada empresa é no uso dos ativos. O ativo de uma empresa, por definição, representa como os recursos foram alocados na expectativa de gerar um benefício futuro, essencialmente trazendo impactos positivos em seu fluxo de caixa. Uma empresa que foca nos negócios mais rentáveis, planeja e executa seus investimentos satisfatoriamente e com custos controlados tenderá a construir uma base de ativos enxuta e eficiente. Desta forma, pressupõe-se que as empresas cujo giro do ativo seja mais alto têm menos custos de agência que suas concorrentes, pois consegue gerar mais receita com o mesmo capital aplicado.

A segunda medida tem objetivo similar, mas tem no numerador uma informação do demonstrativo de resultados, capturando certos gastos correntes das empresas que estão mais sujeitos à discricionariedade dos gestores. As DVG\&A podem revelar o emprego de recursos em regalias e privilégios (perquisites ou private benefits) que não beneficiam os acionistas, como ingressos e/ou camarotes para eventos, aluguel de imóveis nobres e uso de aviões corporativos, por exemplo, além de incluir salário de gestores e funcionários não alocados nos processos produtivos. De forma mais ampla, as DVG\&A também são comumente utilizadas como uma medida do overhead. Espera-se que este indicador, portanto, seja menor para os casos onde o custo de agência é baixo. A Figura 1 apresenta o desenho da pesquisa. 


\begin{tabular}{|c|l|}
\hline Variáveis & \begin{tabular}{|l|}
\hline Resultados Esperados \\
\hline DVG\&A do Ativo
\end{tabular}$\quad \begin{array}{l}\text { Maior para os casos onde o } \\
\text { custo de agência é baixo. } \\
\text { Menor para os casos onde o } \\
\text { custo de agência é baixo. }\end{array}$ \\
\hline
\end{tabular}

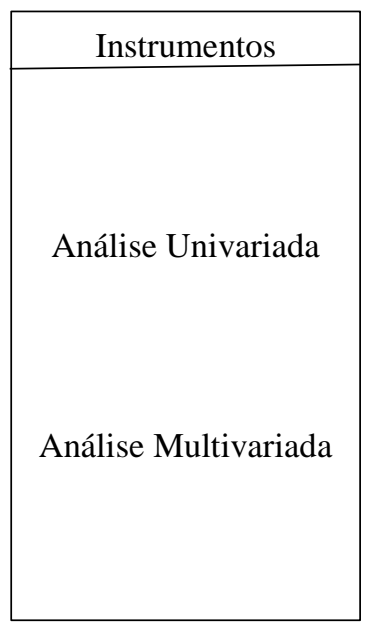

Figura 1. Desenho da Pesquisa

\section{Participação acionária: insiders, blocos e governo}

A origem dos custos de agência se dá na separação entre propriedade (acionistas) e controle (gestores) e decorre do natural desalinhamento de interesses entre estes agentes e do custo inerente ao monitoramento a ser exercido pelos acionistas sobre os gestores. É de se esperar, portanto, que companhias onde parte relevante dos gestores/funcionários seja também acionista (insiders), tenderão a apresentar alinhamento de interesses entre os agentes. Da mesma forma, espera-se que a existência de acionistas com participação relevante (blockholder), aqui definida como acima de 5\%, ainda que não exerçam funções na administração, trará maior controle sobre as decisões dos gestores visto que os benefícios daí decorrentes possivelmente superarão os custos incorridos.

Como proposto por Singh e Davidson (2003), este estudo utiliza o percentual da participação dos insiders no capital da empresa para verificar o potencial alinhamento de interesses existente. De forma similar, o percentual de blockholders foi usado para verificar o nível de controle a ser exercido sobre os gestores pelos acionistas. Em ambos os casos, espera-se que haja menos custos de agência quanto maior for a participação deste tipo de acionista.

Uma importante variável de interesse considerada no presente estudo é a participação do governo do país de origem da companhia de petróleo em seu controle. Este parâmetro reflete o potencial grau de interferência que este governo pode ter sobre as decisões da companhia e visa verificar se o controle governamental de empresas politiza a alocação de recursos e reduz a eficiência (La Porta, Lopez-deSilanes, \& Shleifer, 2002). Espera, portanto, que uma maior participação reflita um maior custo de agência.

\section{Variáveis de controle}

Conforme proposto nos estudos de Singh e Davidson (2003) e Ang et al. (2000), foram consideradas variáveis de controle o tamanho da companhia, medido pelo logaritmo natural das vendas anuais, e a alavancagem, medida pela razão entre dívida e ativo total.

No primeiro caso, o propósito principal é levar em conta possíveis economias de escala decorrentes de diversificação e sinergias. Na amostra utilizada neste estudo encontramos desde companhias independentes focadas em produção de petróleo e/ou gás natural até as majors, que são companhias integradas, atuando em todos os segmentos da cadeia de produção e com faturamento de centenas de bilhões de dólares.

No segundo caso, a alavancagem representa o grau de endividamento da companhia e, portanto, uma boa medida de quanto controle externo os credores exercerão sobre a mesma. Além disso, 
companhias muito endividadas dedicam uma parcela relevante de sua geração de caixa para o serviço da dívida, o que reduz o caixa disponível para os gestores, o que, segundo Jensen (1986) pode reduzir o custo de agência.

Estudos sobre custos de agência indicam a relevância da governança das companhias como fator determinante de seu patamar. Empresas com bons dispositivos de governança, com um Conselho de Administração diligente e alinhado, de fato, com os acionistas, tenderão a ter menores custos de agência. Assim como em Singh e Davidson (2003), o número de membros do conselho de administração, bem como o seu grau de independência foram utilizados como variáveis de controle. O primeiro caso é autoexplicativo, e no segundo caso foi considerado o percentual de membros independentes no conselho.

Enquanto a atuação do conselho de administração e sua composição são reputados como importantes instrumentos de governança, estudos como Gompers, Ishii e Metrick (2003) e Brown e Caylor (2004) propuseram o uso de índices que incorporam múltiplos aspectos de governança, como auditoria, conselho de administração, remuneração dos executivos e dos conselheiros e propriedade. Nesta linha, o presente estudo incluiu uma variável explícita sobre o score de governança das empresas representada pelo Bloomberg ESG Disclosure Score.

A Bloomberg monitora a performance ambiental, social e de governança (Environmental, Social and Governance [ESG]) das companhias abertas e retrata isso através de um score que varia de 0 a 100 , sendo 100 a melhor nota possível.

Especialmente nos casos das empresas que sejam controladas por governos, a existência de políticas bem definidas visando propósitos empresariais em detrimento de direcionamentos políticos momentâneos e de transparência na gestão podem explicar diferenças no custo de agência. A hipótese, neste caso, é que quanto mais alto a pontuação da empresa, menores os custos de agência.

\section{Descrição das variáveis e características da amostra}

A Tabela 1 resume todas as variáveis consideradas neste estudo e traz uma breve descrição de cada uma delas.

Tabela 1

\section{Descrição das Variáveis Consideradas}

\begin{tabular}{ll}
\hline Variável & Descrição \\
\hline Giro & $\begin{array}{l}\text { Giro do Ativo. Calculado pela divisão das vendas anuais pelo ativo total no fim do exercício, ambos } \\
\text { em dólares. Quanto maior o Giro, menores os custos de agência. }\end{array}$ \\
\hline DVG\&A & $\begin{array}{l}\text { Despesas de Vendas, Gerais e Administrativas. Calculado pela divisão das despesas de vendas, } \\
\text { gerais e administrativas anuais pelas vendas anuais, ambas em dólares. Quanto menor a DVG\&A, } \\
\text { menores os custos de agência. }\end{array}$ \\
\hline Insider & $\begin{array}{l}\text { Percentual dos acionistas que são gestores/funcionários da empresa, refletindo maior alinhamento } \\
\text { de interesses. Quanto maior a participação, menores os custos de agência. }\end{array}$ \\
\hline Blocos & $\begin{array}{l}\text { Percentual dos acionistas que possuem mais de } 5 \% \text { na companhia, refletindo maior propensão a } \\
\text { exercer controle sobre os gestores. Quanto maior a participação, menores os custos de agência. }\end{array}$ \\
\hline Governo & $\begin{array}{l}\text { Percentual da participação do governo do país de origem na companhia, refletindo a potencial } \\
\text { interferência sobre as decisões. Quanto maior a participação, maiores os custos de agência. }\end{array}$ \\
\hline Tamanho & $\begin{array}{l}\text { Log das vendas anuais. Variável de controle que busca considerar possíveis economias de escala e } \\
\text { capturar diferenças entre grandes empresas integradas e pequenas especializadas. }\end{array}$ \\
\hline
\end{tabular}




\section{Tabela 1 (continuação)}

\begin{tabular}{|c|c|}
\hline Variável & Descrição \\
\hline Alavancagem & $\begin{array}{l}\text { Alavancagem, calculada pela divisão do endividamento de curto e longo prazo pelo ativo, } \\
\text { ambos em dólares e no fim do exercício. Busca representar o potencial controle exercido pelos } \\
\text { credores, bem como a possível retirada de caixa disponível para os gestores. Maior } \\
\text { alavancagem tenderia, portanto, a ser associada com menores custos de agência. }\end{array}$ \\
\hline Num_CA & $\begin{array}{l}\text { Número de conselheiros no Conselho de Administração. Visa controlar aspectos de } \\
\text { governança, onde uma melhor governança estaria associada a menores custos de agência. }\end{array}$ \\
\hline Indep_CA & $\begin{array}{l}\text { Percentual de membros independentes no Conselho. Visa controlar aspectos de governança, } \\
\text { onde uma melhor governança estaria associada a menores custos de agência. }\end{array}$ \\
\hline ESG_Score & $\begin{array}{l}\text { Índice de performance ambiental, social e de governança. Incluído como uma variável explícita } \\
\text { de controle para a performance das empresas sob estes aspectos e que estariam associados a } \\
\text { menores custos de agência. }\end{array}$ \\
\hline
\end{tabular}

Os parâmetros utilizados neste estudo podem ser genericamente caracterizados de duas formas: (a) aqueles que podem assumir valores extremos e (b) aqueles que variam entre 0 e 1 (ou $0 \%$ e 100\%). No primeiro grupo estão Giro, DVG\&A, Tamanho, Alavancagem e Num_CA, embora valores extremos não sejam esperados neste último. O segundo grupo contém Insider, Blocos, Governo, Indep_CA e ESG_Score.

A Tabela 2 traz estatísticas para estas variáveis considerando a amostra completa das 160 empresas.

Tabela 2

Estatísticas das Variáveis Considerando a Amostra de 160 Empresas

\begin{tabular}{ccccccc}
\hline Variável & Média & Mediana & Máximo & Mínimo & $\begin{array}{c}\text { Desvio } \\
\text { Padrão }\end{array}$ & $\begin{array}{c}\text { Número de } \\
\text { Obs }\end{array}$ \\
\hline Giro & 0,72 & 0,33 & 19,72 & 0,00 & 1,07 & 1.550 \\
DVG\&A & 6,85 & 0,06 & $9.278,00$ & 0,00 & 243,50 & 1.453 \\
Insider & $3,41 \%$ & $0,84 \%$ & $77,42 \%$ & $0,00 \%$ & $8,65 \%$ & 1.025 \\
Blocos & $57,35 \%$ & $60,28 \%$ & $100,00 \%$ & $0,00 \%$ & $27,65 \%$ & 646 \\
Governo & $24,77 \%$ & $0,00 \%$ & $98,13 \%$ & $0,00 \%$ & $31,14 \%$ & 646 \\
Tamanho & 7,66 & 7,52 & 13,06 & $-9,21$ & 2,88 & 1.564 \\
Alavancagem & 0,26 & 0,23 & 3,49 & 0,00 & 0,22 & 1.552 \\
Num_CA & 9,61 & 9,00 & 21,00 & 2,00 & 2,95 & 1.341 \\
Indep_CA & $67,60 \%$ & $75,00 \%$ & $100,00 \%$ & $0,00 \%$ & $22,01 \%$ & 1.319 \\
ESG_Score & 28,85 & 22,57 & 76,35 & 6,64 & 17,34 & 1.310 \\
\hline
\end{tabular}

Para os itens do grupo 2, é razoável que encontremos valores entre 0 e 1 (ou $0 \%$ e 100\%) sem que isto represente um problema nos dados, visto que, por exemplo, a existência de empresas com nenhum controle de insiders ou de blockholders é esperada, assim como também é possível e até esperado que haja empresas 100\% controladas por seus gestores ou por grandes blocos de controle. Estas situações fazem sentido econômico.

Para os itens do grupo 1, no entanto, valores extremos podem denotar situações de pouco sentido econômico e, portanto, um problema para o estudo. Um número de conselheiros zero poderia indicar 
erro nos dados, pois a existência de conselho de administração pressupõe que haja um número mínimo de membros.

Analisando os dados da tabela acima, chama atenção os valores extremos em Giro e DVG\&A, que são as variáveis dependentes do presente estudo. Empresas produtoras de petróleo não apresentam giros de ativo da ordem de 20x, pois usualmente são companhias de capital intensivo com projetos de longa maturação, e não costumam apresentar valores muito próximos a zero, pois suas receitas costumam ser elevadas. De forma similar, o índice DVG\&A (Despesas de Vendas, Gerais e Administrativas / Receita de Vendas) não costuma ser elevado no setor, pois as vendas são usualmente altas para um patamar relativamente baixo de despesas deste tipo.

Tomando por base o $99^{\circ}$ percentil do Giro, duas empresas se destacaram, uma australiana e uma americana. Uma análise mais detalhada de ambas mostrou que seu negócio é focado em distribuição e transporte de petróleo e derivados, o que foge ao escopo deste trabalho. Ambas foram eliminadas do presente estudo. Tomando por base o $2^{\circ}$ percentil do Giro, foram analisadas 6 empresas, todas produtoras de petróleo, mas que passaram por fase de baixo volume de vendas em função da estruturação e maturação de seus respectivos negócios. Estas foram mantidas.

O mesmo padrão de análise foi utilizado para as DVG\&A. Neste caso, nenhuma empresa foi excluída, pois os valores extremos estavam associados ao início/interrupção de suas atividades. Foram retiradas, no entanto, 5 ocorrências onde as vendas anuais foram de menos de US\$ 500 mil dólares. Sendo assim, a Tabela 3 traz os dados atualizados. Percebe-se uma clara redução na média e no desvio padrão das variáveis dependentes Giro e DVG\&A.

Tabela 3

Estatísticas das Variáveis Após Revisões, Considerando 158 Empresas

\begin{tabular}{ccccccc}
\hline Variável & Média & Mediana & Máximo & Mínimo & $\begin{array}{c}\text { Desvio } \\
\text { Padrão }\end{array}$ & $\begin{array}{c}\text { Número de } \\
\text { Obs }\end{array}$ \\
\hline Giro & 0,64 & 0,33 & 4,21 & 0,00 & 0,71 & 1.530 \\
DVG\&A & 0,24 & 0,06 & 39,73 & 0,00 & 1,79 & 1.430 \\
Insider & $3,31 \%$ & $0,84 \%$ & $77,42 \%$ & $0,00 \%$ & $8,32 \%$ & 1.011 \\
Blocos & $57,14 \%$ & $60,28 \%$ & $100,00 \%$ & $0,00 \%$ & $27,67 \%$ & 637 \\
Governo & $25,12 \%$ & $0,00 \%$ & $98,13 \%$ & $0,00 \%$ & $31,22 \%$ & 637 \\
Tamanho & 7,64 & 7,50 & 13,06 & $-9,21$ & 2,89 & 1.544 \\
Alavancagem & 0,27 & 0,23 & 3,49 & 0,00 & 0,22 & 1.532 \\
Num_CA & 9,64 & 9,00 & 21,00 & 2,00 & 2,94 & 1.324 \\
Indep_CA & $67,66 \%$ & $75,00 \%$ & $100,00 \%$ & $0,00 \%$ & $22,09 \%$ & 1.302 \\
ESG_Score & 28,94 & 22,41 & 76,35 & 6,64 & 17,41 & 1.293 \\
\hline
\end{tabular}

Verificou-se, ainda, que a variável Insider não possui observações válidas para os anos de 2007 a 2009. Este problema decorre da indisponibilidade destes dados nas bases de dados selecionadas para este trabalho e, embora não tenha sido possível corrigir este problema, os demais dados referentes a este período foram mantidos. Esta característica, no entanto, limitou o período de análise das regressões multivariadas em painel a 7 anos (2010 a 2016), pois esta variável faz parte de todos os modelos propostos.

\section{Análise univariada e multivariada}

Inicialmente, verifica-se as relações entre as variáveis selecionadas e as variáveis dependentes através da diferença entre as médias de subgrupos. Após essa análise univariada, utiliza-se regressão de 
dados em painel, considerando as características dos dados em cross-section e temporais. Como a base de dados não apresenta informações para todas as variáveis em todos os anos observados, o painel é considerado não balanceado.

Para verificar a existência de efeitos omitidos foram utilizados os testes de Breusch-Pagan, Honda, King Wu e Gourieroux et al. (LM tests for random effects). Em seguida, a análise da técnica mais adequada foi feita com a aplicação do teste de Hausman, que testa se o efeito aleatório é mais adequado (não há correlação do fator omitido com as variáveis do modelo). Caso haja indicação de uso da técnica de efeitos fixos, aplicou-se ainda o teste de redundância para efeitos fixos.

Também foi avaliada a presença de heterocedasticidade, que embora não cause viés nos coeficientes estimados, afeta a sua variância e, portanto, invalida o desvio padrão e consequentemente sua significância. Os testes de Breusch-Pagan e de White foram utilizados para verificar este potencial problema e a ocorrência de heterocedasticidade foi tratada aplicando a correção de White.

Seguindo a metodologia adotada por Singh e Davidson (2003), foram propostos 4 modelos de acordo com as equações (1) a (4) listadas. A variável dependente $Y_{i t}$ é o indicador de custo de agência (Giro ou DVG\&A). Adicionalmente, $a_{i}$ representa os efeitos individuais e $v_{i t}$ os erros idiossincráticos, enquanto $b_{t}$ os efeitos temporais.

A equação (1) considera as variáveis independentes Insider, Blocos e Governo e as variáveis de controle Tamanho e Alavancagem. As equações (2), (3) e (4) consideram uma variável de controle adicional cada, respectivamente ESG_Score, Num_CA e Indep_CA. Os índices i e $\mathbf{t}$ representam a empresa (cross-section) e o ano (período) respectivamente. O programa utilizado foi o Eviews.

$$
\begin{gathered}
Y_{i t}=c+\beta_{1} \text { Insider }_{i t}+\beta_{2} \text { Blocos }_{i t}+\beta_{3} \text { Governo }_{i t}+\beta_{4} \text { Tamanho }_{i t}+ \\
\beta_{5} \text { Alavancagem }_{i t}+a_{i}+b_{t}+v_{i t} \\
Y_{i t}=c+\beta_{1} \text { Insider }_{i t}+\beta_{2} \text { Blocos }_{i t}+\beta_{3} \text { Governo }_{i t}+\beta_{4} \text { ESG }_{\text {Score }_{i t}}+ \\
\beta_{5} \text { Tamanho }_{i t}+\beta_{6} \text { Alavancagem }_{i t}+a_{i}+b_{t}+v_{i t} \\
Y_{i t}=c+\beta_{1} \text { Insider }_{i t}+\beta_{2} \text { Blocos }_{i t}+\beta_{3} \text { Governo }_{i t}+\beta_{4} \text { Num }_{-} \text {CA }_{i t}+ \\
\beta_{5} \text { Tamanho }_{i t}+\beta_{6} \text { Alavancagem }_{i t}+a_{i}+b_{t}+v_{i t} \\
Y_{i t}=c+\beta_{1} \text { Insider }_{i t}+\beta_{2} \text { Blocos }_{i t}+\beta_{3} \text { Governo }_{i t}+\beta_{4} \text { Indep }_{-} \text {CA }_{i t}+ \\
\beta_{5} \text { Tamanho }_{i t}+\beta_{6} \text { Alavancagem }_{i t}+a_{i}+b_{t}+v_{i t}
\end{gathered}
$$

\section{Resultados}

\section{Análise univariada}

A primeira análise das relações entre os parâmetros estudados foi feita verificando a diferença entre as médias de subgrupos das variáveis dependentes Giro e DVG\&A. As observações foram divididas em dois grupos: acima ou abaixo da mediana de cada variável explicativa ou de controle. Em seguida, foram computadas as médias do Giro e da DVG\&A para cada destes subgrupos e calculadas as estatísticas t da diferença entre as médias para avaliar se é possível rejeitar a hipótese de que estas sejam zero. 
Tabela 4

Giro do Ativo - Comparação das Médias

\begin{tabular}{ccccccc}
\hline Variável & $\begin{array}{c}\text { Média do } \\
\text { Giro Acima } \\
\text { da Mediana } \\
\text { da Variável }\end{array}$ & $\begin{array}{c}\text { Número de } \\
\text { Observações }\end{array}$ & $\begin{array}{c}\text { Média do } \\
\text { Giro Abaixo } \\
\text { da Mediana } \\
\text { da Variável }\end{array}$ & $\begin{array}{c}\text { Número de } \\
\text { Observações }\end{array}$ & $\begin{array}{c}\text { Diferença das } \\
\text { Médias }\end{array}$ & $\begin{array}{c}\text { Estatística t } \\
\text { da Diferença }\end{array}$ \\
\hline Insider & 0,33 & 499 & 0,88 & 504 & $-0,55$ & $-13.9688^{* * *}$ \\
Blocos & 1,01 & 311 & 0,79 & 316 & 0,22 & $3.4699^{* * *}$ \\
Governo & 1,12 & 271 & 0,72 & 361 & 0,40 & $6.3749^{* * *}$ \\
ESG_Score & 0,85 & 645 & 0,49 & 646 & 0,36 & $9.2142^{* * *}$ \\
Num_CA & 0,80 & 585 & 0,55 & 515 & 0,26 & $5.9716^{* * *}$ \\
Indep_CA & 0,53 & 636 & 0,81 & 640 & $-0,28$ & $-7.0538^{* * *}$ \\
Tamanho & 1,00 & 766 & 0,28 & 764 & 0,72 & $22.7604 * * *$ \\
Alavancagem & 0,58 & 765 & 0,71 & 765 & $-0,13$ & $-3.5166^{* * *}$ \\
\hline
\end{tabular}

Nota. Essa Tabela apresenta os resultados da comparação univariada das médias para a variável dependente Giro, medida pela razão das vendas anuais/ativo total. A descrição das variáveis encontra-se na Tabela 1. A estatística t é apresentada na coluna mais à direita.

$*, * * \mathrm{e}^{* * *}$ representam, respectivamente, a significância estatística a $10 \%, 5 \%$ e $1 \%$.

A Tabela 4 apresenta a análise para o Giro do Ativo e indica que todas as diferenças são estatisticamente significantes a $1 \%$. Esta análise preliminar aponta que empresas que possuem relevantes blocos de controle, maior participação do governo do país de origem, pontuação mais alta no índice de governança e boards mais numerosos são mais eficientes no uso de seus ativos para gerar receita. Por outro lado, as empresas com maior participação de insiders e maior proporção de conselheiros independentes são menos eficientes. As variáveis de controle Tamanho e Alavancagem indicam que as empresas maiores e as menos alavancadas tendem a ser mais eficientes sob este mesmo parâmetro.

Dentre as variáveis relacionadas à estrutura de controle e governança, os resultados encontrados estão de acordo com a hipótese inicial para a participação de blockholders e score de governança, mas são diferentes para a participação de insiders, para o número de conselheiros, para o grau de independência do conselho de administração e, ainda, para a participação do governo do país de origem nas empresas.

A Tabela 5 apresenta a mesma análise para as DVG\&A. Neste caso, há indicação de que empresas que possuem relevantes blocos de controle, maior participação do governo do país de origem, pontuação mais alta no índice de governança, boards mais numerosos e com mais independência têm menor gasto com despesas discricionárias e, portanto, teriam menores custos de agências. Empresas com maior participação de insiders, por sua vez, são menos eficientes. As variáveis de controle Tamanho e Alavancagem indicam que as empresas maiores e as mais alavancadas têm menores custos de agência medidos pelas DVG\&A.

Os resultados estão de acordo com o esperado para as variáveis Blocos, score de governança e grau de independência do conselho de administração, embora as diferenças de Blocos e grau de independência do conselho de administração não sejam estatisticamente significantes mesmo a $10 \%$. Novamente número de conselheiros, participação de insiders e Governo apresentaram resultados diferentes do esperado. 
Tabela 5

Despesas de Vendas, Gerais e Administrativas - Comparação das Médias

\begin{tabular}{ccccccc}
\hline Variável & $\begin{array}{c}\text { Média da } \\
\text { DVG\&A } \\
\text { Acima da } \\
\text { Mediana da } \\
\text { Variável }\end{array}$ & $\begin{array}{c}\text { Número de } \\
\text { Observações }\end{array}$ & $\begin{array}{c}\text { Média da } \\
\text { DVG\&A } \\
\text { Abaixo da } \\
\text { Mediana da } \\
\text { Variável }\end{array}$ & $\begin{array}{c}\text { Número de } \\
\text { Observações }\end{array}$ & $\begin{array}{c}\text { Diferença das } \\
\text { Médias }\end{array}$ & $\begin{array}{c}\text { Estatística t } \\
\text { da Diferença }\end{array}$ \\
\hline Insider & 0,39 & 496 & 0,07 & 496 & 0,32 & $2.6786^{* * *}$ \\
Blocos & 0,20 & 287 & 0,39 & 301 & $-0,19$ & -0.9632 \\
Governo & 0,06 & 253 & 0,47 & 340 & $-0,41$ & $-2.0542^{* *}$ \\
ESG_Score & 0,06 & 629 & 0,27 & 611 & $-0,20$ & $-2.7893^{* * *}$ \\
Num_CA & 0,08 & 559 & 0,27 & 498 & $-0,19$ & $-2.2717^{* *}$ \\
Indep_CA & 0,15 & 620 & 0,18 & 606 & $-0,04$ & -0.5036 \\
Tamanho & 0,06 & 738 & 0,44 & 692 & $-0,37$ & $-3.9709^{* * *}$ \\
Alavancagem & 0,15 & 712 & 0,34 & 715 & $-0,19$ & $-1.9597^{*}$ \\
\hline
\end{tabular}

Nota. Essa tabela apresenta os resultados da comparação univariada das médias para a variável dependente DVG\&A, medida pela razão das despesas de vendas, gerais e administrativas anuais/vendas anuais. A descrição das variáveis encontra-se na Tabela 1. A estatística t é apresentada na coluna mais à direita.

$*, * * \mathrm{e}^{* * *}$ representam, respectivamente, a significância estatística a $10 \%, 5 \%$ e $1 \%$.

Considerando o foco deste estudo e os resultados diferentes da hipótese inicial para a variável Governo, foi feita uma análise adicional da participação dos governos nas empresas levando em conta o tamanho das companhias, como pode ser visto nas duas tabelas abaixo. Na Tabela 6, em que comparamos o giro do ativo, é possível notar que o resultado está de acordo com o esperado apenas para o quartil superior (75\%-100\%) e a diferença é estatisticamente significante a $1 \%$. Neste grupo, as empresas que possuem maior participação estatal apresentam um Giro médio de 1,18, enquanto as que apresentam menor participação estatal apresentam um Giro de 1,46.

Tabela 6

Giro do Ativo - Comparação das Médias Relacionadas ao \% do Governo por Tamanho

\begin{tabular}{cccccccc}
\cline { 3 - 8 } & \multicolumn{5}{c}{ Giro do Ativo - Comparação das Médias por Tamanho } \\
\hline $\begin{array}{c}\text { Quartil } \\
\text { Tamanho }\end{array}$ & Variável & $\begin{array}{c}\text { Média do } \\
\text { Giro Acima } \\
\text { da Mediana } \\
\text { da Variável }\end{array}$ & $\begin{array}{c}\text { Número de } \\
\text { Observações }\end{array}$ & $\begin{array}{c}\text { Média do } \\
\text { Ga Abaixo } \\
\text { da Mediana } \\
\text { da Variável }\end{array}$ & $\begin{array}{c}\text { Número de } \\
\text { Observações }\end{array}$ & $\begin{array}{c}\text { Diferença } \\
\text { das Médias }\end{array}$ & $\begin{array}{c}\text { Estatística t } \\
\text { da } \\
\text { Diferença }\end{array}$ \\
\hline $0 \%-25 \%$ & Governo & - & - & 0,47 & 97 & - & - \\
$25 \%-50 \%$ & Governo & 0,38 & 11 & 0,29 & 106 & 0,09 & $2.3909 * *$ \\
$50 \%-75 \%$ & Governo & 1,11 & 103 & 0,69 & 59 & 0,41 & $2.9414^{* * *}$ \\
$75 \%-100 \%$ & Governo & 1,18 & 157 & 1,46 & 99 & $-0,28$ & $-3.153^{* * *}$ \\
\hline
\end{tabular}

Nota. Essa tabela apresenta os resultados da comparação univariada das médias para a variável dependente Giro, medida pela razão das vendas anuais/ativo total, focando na variável independente Governo. A descrição das variáveis encontra-se na Tabela 1. A coluna mais à esquerda indica o agrupamento das observações pela variável Tamanho. A estatística t é apresentada na coluna mais à direita.

$*, * * \mathrm{e}^{* * *}$ representam, respectivamente, a significância estatística a $10 \%, 5 \%$ e $1 \%$. 
Na Tabela 7, em que comparamos as DVG\&A, é possível notar que o resultado está de acordo com o esperado nos três quartis superiores $(25 \%-50 \%$; $50 \%-75 \%$; e $75 \%-100 \%$ ) e a diferença é estatisticamente significante em dois deles. Nestes três grupos, as empresas que possuem maior participação estatal apresentam maiores despesas que as demais, indicando mais custos de agência. Nota-se, no entanto, que as empresas privadas do quartil inferior apresentam DVG\&A médio de 1,71, muito acima dos demais. Isto decorre de empresas que estavam iniciando/interrompendo suas atividades e tiveram valores baixos de vendas em determinados anos, impactando o indicador DVG\&A.

Tabela 7

DVG\&A - Comparação das Médias Relacionadas ao \% do Governo por Tamanho

\begin{tabular}{|c|c|c|c|c|c|c|c|}
\hline \multirow[b]{2}{*}{$\begin{array}{c}\text { Quartil } \\
\text { Tamanho }\end{array}$} & \multirow[b]{2}{*}{ Variável } & \multicolumn{6}{|c|}{ Despesas de Vendas, Gerais e Administrativas - Comparação das Médias por Tamanho } \\
\hline & & $\begin{array}{c}\text { Média da } \\
\text { DVG\&A } \\
\text { Acima da } \\
\text { Mediana da } \\
\text { Variável }\end{array}$ & $\begin{array}{l}\text { Número de } \\
\text { Observaçōes }\end{array}$ & $\begin{array}{c}\text { Média da } \\
\text { DVG\&A } \\
\text { Abaixo da } \\
\text { Mediana da } \\
\text { Variável }\end{array}$ & $\begin{array}{l}\text { Número de } \\
\text { Observações }\end{array}$ & $\begin{array}{c}\text { Diferença } \\
\text { das Médias }\end{array}$ & $\begin{array}{l}\text { Estatística t } \\
\text { da Diferença }\end{array}$ \\
\hline $0 \%-25 \%$ & Governo & - & - & 1,71 & 86 & - & - \\
\hline $25 \%-50 \%$ & Governo & 0,11 & 8 & 0,06 & 104 & 0,05 & $2.551 * *$ \\
\hline $50 \%-75 \%$ & Governo & 0,08 & 89 & 0,05 & 58 & 0,04 & $4.0826 * * *$ \\
\hline $75 \%-100 \%$ & Governo & 0,04 & 156 & 0,04 & 92 & 0,001 & 0.2209 \\
\hline $25 \%-100 \%$ & Governo & 0,06 & 253 & 0,05 & 254 & 0,01 & $2.0113 * *$ \\
\hline
\end{tabular}

Nota. Essa tabela apresenta os resultados da comparação univariada das médias para a variável dependente DVG\&A, medida pela razão das despesas de vendas, gerais e administrativas anuais/vendas anuais, focando na variável independente Governo. A descrição das variáveis encontra-se na Tabela 1. A coluna mais à esquerda indica o agrupamento das observações pela variável Tamanho. A estatística t é apresentada na coluna mais à direita.

$*, * * \mathrm{e}^{* * *}$ representam, respectivamente, a significância estatística a $10 \%, 5 \%$ e $1 \%$.

\section{Análise multivariada}

Os resultados da análise multivariada são exibidos nas Tabelas 8 (Giro do Ativo) e 9 (Despesas de Vendas, Gerais e Administrativas) a seguir. É aplicado o teste VIF para verificar a existência de multicolinearidade.

\section{Giro de ativo}

Tabela 8

Custos de Agência Medidos pelo Giro do Ativo

\begin{tabular}{ccccc}
\hline \multicolumn{5}{c}{ Análise do Giro do Ativo } \\
\hline Regressão (Modelo) & $\mathbf{1}$ & $\mathbf{2}$ & $\mathbf{3}$ & $\mathbf{4}$ \\
\hline Insider & -0.7977 & -0.2525 & -0.3263 & -0.3723 \\
& $(-1.31)$ & $(-0.49)$ & $(-0.61)$ & $(-0.74)$ \\
\multirow{2}{*}{ Bloco } & $0.0964^{*}$ & 0.0715 & 0.0871 & $0.1068^{*}$ \\
& $(1.73)$ & $(1.16)$ & $(1.45)$ & $(1.84)$ \\
\multirow{2}{*}{ Governo } & $-0.2681^{*}$ & -0.2239 & $-0.2803^{* *}$ & -0.1506 \\
& $(-1.87)$ & $(-1.46)$ & $(-2.02)$ & $(-0.99)$ \\
\hline
\end{tabular}




\section{Tabela 8 (continuação)}

\begin{tabular}{ccccc}
\hline Regressão (Modelo) & $\mathbf{1}$ & $\mathbf{2}$ & $\mathbf{3}$ & $\mathbf{4}$ \\
\hline ESG_Score & - & 0.0021 & - & - \\
& - & $(0.83)$ & - & - \\
Num_CA & - & - & -0.0053 & - \\
& - & - & $(-0.64)$ & - \\
Indep_CA & - & - & - & $-0.3006^{*}$ \\
& - & - & - & $(-1.9)$ \\
Tamanho & $0.0434^{* * *}$ & $0.0368^{* * *}$ & $0.0375^{* * *}$ & $0.036^{* * *}$ \\
& $(3.36)$ & $(3.16)$ & $(3.08)$ & $(2.96)$ \\
Alavancagem & $-0.258^{* *}$ & $-0.2669^{* *}$ & $-0.2164^{*}$ & -0.1641 \\
& $(-2.25)$ & $(-2.12)$ & $(-1.8)$ & $(-1.38)$ \\
Constante & $0.5577^{* * *}$ & $0.5483^{* * *}$ & $0.6763^{* * *}$ & $0.7463^{* * *}$ \\
& $(4.5)$ & $(3.7)$ & $(4.5)$ & $(5.65)$ \\
\hline Modelo & Fixo & Fixo & Fixo & Fixo \\
R ${ }^{2}$ & 0,95 & 0,96 & 0,96 & 0,96 \\
R $^{2}$ Ajustado & 0,94 & 0,95 & 0,94 & 0,95 \\
Estatística F & 87,9132 & 89,9160 & 89,3302 & 89,9148 \\
\hline
\end{tabular}

Nota. Essa tabela apresenta os resultados da regressão em painel para a variável dependente Giro, medida pela razão das vendas anuais/ativo total. A descrição das variáveis encontra-se na Tabela 1. A estatística t é apresentada entre parênteses abaixo dos coeficientes.

*, ** e *** representam, respectivamente, a significância estatística do coeficiente associado a 10\%, 5\% e $1 \%$.

Os coeficientes da variável Bloco são sempre positivos, indicando, como previsto, que a presença de blockholders aumenta a eficiência no uso dos ativos. Há significância estatística nos modelos 1 e 4. Singh e Davidson (2003) e Mcknight e Weir (2009) reportaram relação positiva entre estas variáveis, porém sem significância estatística.

A maior participação do governo do país de origem reduz a eficiência supracitada. Neste caso, há significância estatística nos modelos 1 e 3 . A participação de funcionários no controle da companhia (Insider) apresentou sinal negativo em todos os casos, mas não tem significância estatística em nenhum momento. A literatura sugere que esse resultado pode ser influenciado pelos interesses conflitantes das relações multinacionais do agente principal, a multiplicidade de metas e o risco natural que advém do vínculo estreito com o governo (Calabrò \& Torchia, 2011; Christensen \& Lægreid, 2014). Além disso, o conflito principal-agente nesse caso é subordinado ao conflito principal-principal, pelo predomínio da estrutura de propriedade concentrada, decorrente da participação governamental, o que geralmente demanda métricas de controle mais elaboradas ou que sacrifica determinadas métricas em detrimento de informação a todos os stakeholders.

A variável de controle Tamanho tem sinal positivo e elevada significância em todos os modelos, enquanto Alavancagem possui sinal negativo e é significante nas três primeiras regressões. Isto é perfeitamente consistente com os achados de Singh e Davidson (2003) e sugere que empresas maiores são capazes de gerar mais recursos com a mesma base de ativos enquanto as companhias muito alavancadas têm esta característica prejudicada. Mcknight e Weir (2009) encontraram a mesma relação positiva para o tamanho, contudo a relação foi inversa para a alavancagem.

Em relação às variáveis de controle relacionadas a governança, score de governança e número de conselheiros (Num_CA) apresentaram o sinal esperado, embora não possuam significância estatística. 
O índice de governança é uma proxy para a existência de políticas bem definidas visando propósitos empresariais e transparência na gestão e, portanto, um índice mais alto aumenta o giro do ativo. $\mathrm{O}$ maior número de conselheiros, por sua vez, tem o impacto oposto, como indicado por Singh e Davidson (2003) e Yermack (1996).

A variável grau de independência do conselho de administração (Indep_CA), no entanto, apresentou um resultado significante e diferente do esperado, ou seja, um conselho mais independente seria não benéfico ao uso eficiente dos ativos, contrariando as melhores práticas sugeridas para governança. Dentre as possíveis explicações para este resultado temos que os conselheiros independentes não estão familiarizados/qualificados para atuar especificamente na indústria de petróleo (information gap $)^{3}$ ou que não estão atuando com independência de fato (cooptados pelos demais) ${ }^{4}$. Singh e Davidson (2003) e Mcknight e Weir (2009) não encontraram significância estatística para a independência do conselho quando avaliando o giro do ativo.

Em função dos elevados $\mathrm{R}^{2}$, foi feita uma análise da correlação entre as variáveis independentes e de controle. A variável Tamanho apresentou correlação entre 0,40 e 0,47 com três variáveis e, por isso, modelos alternativos sem Tamanho foram testados. Os resultados obtidos para os coeficientes, sinais e significâncias foram muito semelhantes, exceto para a variável Insider nos modelos 2, 3 e 4, onde a variação do coeficiente e significância foi mais elevada, embora a insignificância estatística nestes casos permaneceu.

Em suma, os resultados sugerem que quando levamos em conta características da composição societária e de governança, em média, grandes companhias produtoras de petróleo, com baixa alavancagem, grandes blocos acionários e sem participação dos governos de seus países de origem no controle conseguem girar o seu ativo mais eficientemente. Apesar disso, é importante destacar que a literatura aponta que empresas estatais demandam requerimentos específicos para avaliação de sua governança (Estrin \& Pérotin, 1991; Lynn, Heinrich, \& Hill, 2000) e que as pesquisas empíricas nessa área ainda estão em uma fase bem incipiente (Grossi, Papenfuß, \& Tremblay, 2015).

\section{Despesas de vendas, gerais e administrativas}

Tabela 9

Custos de Agência Medidos pelas Despesas de Vendas, Gerais e Administrativas

\begin{tabular}{ccccc}
\hline \multicolumn{5}{c}{ Análise das Despesas de Vendas, Gerais e Administrativas } \\
\hline Regressão (Modelo) & $\mathbf{1}$ & $\mathbf{2}$ & $\mathbf{3}$ & $\mathbf{4}$ \\
\hline Insider & 9.7199 & 21.8341 & 21.7411 & 21.7744 \\
& $(0.8)$ & $(1.54)$ & $(1.55)$ & $(1.55)$ \\
\multirow{2}{*}{ Bloco } & 0.795 & -0.5791 & -0.5063 & -0.495 \\
& $(0.75)$ & $(-1.21)$ & $(-1.1)$ & $(-1.06)$ \\
\multirow{2}{*}{ Governo } & 1.6444 & 1.0079 & 0.6667 & 1.0685 \\
& $(1.31)$ & $(1.44)$ & $(0.97)$ & $(1.29)$ \\
ESG_Score & - & 0.0108 & - & - \\
& - & $(1.47)$ & - & - \\
Num_CA & - & - & -0.0356 & - \\
& - & - & $(-0.68)$ & - \\
\hline
\end{tabular}




\section{Tabela 9 (continuação)}

\begin{tabular}{ccccc}
\hline Regressão (Modelo) & $\mathbf{1}$ & $\mathbf{2}$ & $\mathbf{3}$ & $\mathbf{4}$ \\
\hline Indep_CA & - & - & - & -0.8068 \\
& - & - & - & $(-1.18)$ \\
Tamanho & $-2.6443^{* * *}$ & $-2.233^{*}$ & $-2.1792^{*}$ & $-2.1994^{*}$ \\
& $(-2.45)$ & $(-1.84)$ & $(-1.83)$ & $(-1.83)$ \\
Alavancagem & -4.3163 & $-1.5589^{* *}$ & $-1.3403^{*}$ & -1.1499 \\
& $(-1.63)$ & $(-2.04)$ & $(-1.83)$ & $(-1.53)$ \\
Constante & $23.3391^{* * *}$ & $19.536^{*}$ & $19.907^{*}$ & $19.9813^{*}$ \\
& $(2.49)$ & $(1.85)$ & $(1.84)$ & $(1.85)$ \\
\hline Modelo & Fixo & Fixo & Fixo & Fixo \\
R & 0,52 & 0,51 & 0,50 & 0,50 \\
$\mathrm{R}^{2}$ Ajustado & 0,42 & 0,39 & 0,39 & 0,39 \\
Estatística F & 5,1536 & 4,4640 & 4,5185 & 4,4829 \\
\hline
\end{tabular}

Nota. Essa tabela apresenta os resultados da regressão em painel para a variável dependente DVG\&A, medida pela razão das despesas de vendas, gerais e administrativas anuais/vendas anuais. A descrição das variáveis encontra-se na Tabela 1. A estatística t é apresentada entre parênteses abaixo dos coeficientes.

*, ** e *** representam, respectivamente, a significância estatística do coeficiente associado a 10\%, 5\% e $1 \%$.

Quando analisamos as DVG\&A na Tabela 9, é importante ter em mente que a relação de sinais esperados é invertida quando comparamos com a análise do Giro. Isto porque um valor maior da razão DVG\&A/Vendas Anuais é interpretada como maiores custos de agência.

Embora não haja significância estatística em nenhum dos modelos propostos para as variáveis Insider, Blocos e Governo, os coeficientes estão, via de regra, consistentes com os achados para o giro dos ativos. Para Insider e Governo, uma maior participação destes tipos de acionistas levaria a maiores custos de agência, enquanto que uma maior presença de blocos de controle reduziria os custos de agência, sendo a única exceção para este último o modelo 1.

A variável de controle Tamanho tem sinal negativo e elevada significância em quase todos os modelos, o que também é consistente com os achados anteriores. Alavancagem também tem o sinal negativo em todos os casos e é significante nas regressões 2 e 3 . Nas regressões 1 e 4 o seu p-valor é de $11 \%$ e $13 \%$ respectivamente. Diferentemente do seu significado quando analisamos o giro do ativo, os resultados agora sugerem que uma maior alavancagem levaria a menores custos de agência medidos pelas despesas de vendas, gerais e administrativas. Isto também ocorreu no estudo de Singh e Davidson (2003) e de Mcknight e Weir (2009) e está de acordo com Jensen (1986), que sugeriu que o peso do serviço da dívida em uma companhia alavancada levaria os gestores a serem extremamente eficientes, reduzindo o custo de agência, como uma forma de cumprir com suas obrigações e preservar suas posições.

É plausível que esta relação fique perceptível quando avaliamos as DVG\&A porque estas representam gastos discricionários que tendem a responder mais rapidamente à ação dos gestores, além de englobarem custos eventualmente expropriatórios (regalias e privilégios). Estas características não são tão marcantes quando avaliamos a base de ativos de uma empresa, que é formada a partir de decisões com impacto de longo prazo e que podem acarretar certa inércia em sua reversão.

Em relação às variáveis de controle relacionadas a governança, apenas grau de independência do conselho de administração apresentou o sinal esperado, mas sem significância estatística, assim como número de conselheiros e score de governança. Por conta de resultados similares a esse estudo, a literatura tem avançado em métricas específicas para analisar a governança de empresas estatais, bem 
como medidas de desempenho que tenham em conta os objetivos não econômicos destas empresas (Bhasa, 2015; Ting \& Lean, 2015). Além disso, fatores como características legais, culturais e decisões políticas influenciam a governança da empresa de tal forma que sugerem a dificuldade de comparação mesmo de métricas objetivas como os gastos discricionários (Liu, Uchida, \& Yang, 2012; Peda, Grossi, \& Liik, 2013). Por último, a própria motivação de não existir interesse privado no setor, ou existir apenas de forma reduzida, pode impactar o desempenho da empresa estatal (Cuervo-Cazurra \& Dau, 2009; Nheri, 2014).

\section{Conclusões}

Este estudo analisou a influência da participação estatal no controle de empresas petrolíferas listadas em bolsas americanas sobre os seus custos de agência, levando em conta características das empresas que podem influenciar esta relação, como aspectos de governança, alavancagem e tamanho. Para isto, foi utilizada a técnica de regressão de dados em painel com a amostra de empresas de diversos países no período de 2010 a 2016.

Medindo os custos de agência pela eficiência no uso dos ativos, os resultados trazem indícios que suportam a hipótese de que a participação dos governos na estrutura de controle exerce uma influência negativa. Quando consideramos a medida de gastos discricionários DVG\&A, no entanto, não foi estabelecida uma relação significativa estatisticamente, ainda que os coeficientes tenham os sentidos previstos. Estes resultados estão em linha com as ideias e proposições de Shleifer e Vishny (1994, 1997), Shleifer (1998) e La Porta et al. (2002).

Houve, ainda, indícios de que a presença de blocos de controle acima de 5\% das ações tem impacto positivo sobre os custos de agência, diferentemente dos achados de Singh e Davidson (2003), que reportaram resultados não significativos. De forma inversa, não houve evidências de uma relação significativa entre a presença de insiders no controle das empresas e menores custos de agência, como concluído no estudo de 2003.

No tocante às variáveis de controle relacionadas a governança, índice ESG, número de conselheiros e independência do conselho, apenas esta última apresentou resultados significativos, mas diferentes do previsto por Fama e Jensen (1983), indicando que maior independência do board estaria associada com maiores custos de agência. Possíveis explicações para este resultado podem ser a existência de information gap ou a cooptação dos conselheiros independentes, como proposto por Duchin, Matsusaka e Ozbas (2010) e por Coles, Daniel e Naveen (2014) respectivamente.

Em relação à alavancagem e ao tamanho das empresas, os resultados foram similares aos de Singh e Davidson (2003). Maior proporção de endividamento levou a um menor giro do ativo, mas também está associada a menores despesas discricionárias, este último resultado em linha com Jensen (1986). Empresas grandes, por sua vez, fazem em média melhor uso de sua base de ativos e ao mesmo tempo conseguem reduzir suas despesas.

É importante destacar que a mensuração da eficiência do uso de ativos por parte de estatais é sempre muito complicada pela influência de interesses conflitantes das relações multinacionais do agente principal, pela multiplicidade de metas e pelo risco natural que advém do vínculo estreito com o governo. Além disso, nesse caso, o conflito principal-agente é subordinado ao conflito principalprincipal, pelo predomínio da estrutura de propriedade concentrada, o que acarreta no sacrifício de determinadas métricas em detrimento de informação a todos os stakeholders.

Uma preocupação natural com os resultados é a possibilidade de causalidade reversa. Desta forma, os resultados poderiam estar influenciados pelo fato de empresas com maior participação estatal existam em países ou áreas em que o giro do ativo seja menor ou as despesas administrativas sejam maiores. A definição de uma amostra controlada, listada em bolsas americanas, é uma tentativa de minimizar esse problema. Entretanto, identificamos essa característica como uma limitação do trabalho. 
Como sugestão de trabalhos futuros, apontamos a possibilidade de identificação do desempenho de empresas de petróleo estatais em diferentes condições político-econômicas, sob a perspectiva macroeconômica.

\section{Notas}

${ }^{1}$ Este problema ocorre quando é possível receber os benefícios de um recurso comum/coletivo sem ter de arcar com seus custos. Neste caso específico, um pequeno acionista não tem incentivos a monitorar e controlar os gestores de uma empresa, pois arcaria com estes elevados custos e somente teria um ganho proporcional à sua participação. Os demais acionistas, no entanto, ganhariam sem pagar nada.

${ }^{2} \mathrm{D}$ - Unnamed private shareholders, aggregated: inclui ocorrências com mais de um acionista privado dsignado de forma coletiva (private citizens, private shareholders in country X, etc). L - Other unnamed shareholders, aggregated: inclui mais de um acionista não nomeado (other shareholders, companies, associations, private persons, etc). Z - Public: usado para companhias públicas, agregando acionistas diferentes não identificados de forma individual.

${ }^{3}$ Duchin et al. (2010) verificam se o impacto de conselheiros independentes é influenciado pela dificuldade de aprender sobre a companhia, concluindo que se é custoso adquirir este conhecimento, um maior número de outsiders no conselho piora a performance.

${ }^{4}$ Coles et al. (2014) estudam se os conselheiros independentes que assumiram durante a gestão do CEO são de fato independentes. Partindo da premissa que estes estariam em dívida com o CEO por conseguir o cargo, eles concluem que há uma relação positiva entre a proporção deste tipo de conselheiro e a remuneração do CEO e negativa com a remuneração baseada em performance e a substituição do CEO.

\section{Referências}

Almeida, R. S., Klotzle, M. C., \& Pinto, A. C. (2013). Composição do conselho de Administração no setor de energia elétrica do Brasil. Revista de Administração da UNIMEP, 11(1), 156-180. http://doi.org/10.15600/1679-5350/rau.v11n1p156-180

Andrade, L. P., Salazar, G. T., Calegario, C. L. L., \& Silva, S. S. (2009). Governança corporativa: Uma análise da relação do conselho de administração com o valor de mercado e desempenho das empresas brasileiras. Revista de Administração Mackenzie, 10(4), 4-31. http://doi.org/10.1590/S1678-69712009000400002

Ang, J. S., Cole, R. A., \& Lin, J. W. (2000). Agency costs and ownership structure. The Journal of Finance, 55(1), 81-106. https://doi.org/10.1111/0022-1082.00201

Bernardino, F. F., Peixoto, F. M., \& Nascimento, R. F. (2015). Governança e eficiência em empresas do setor elétrico brasileiro. Revista Pretexto, 16(1), 36-51. http://doi.org/10.21714/pretexto.v16i1.2086

Beuselinck, C., Cao, L., Deloof, M., \& Xia, X. (2017). The value of government ownership during the global financial crisis. Journal of Corporate Finance, 42, 481-493. https://doi.org/10.1016/j.jcorpfin.2015.05.002

Bhasa, M. P. (2015). Ownership structure and performance of listed state-owned enterprises vis-à-vis comparable private enterprises: Evidence from India. Journal of Corporate Governance, 14(3), 7-24.

Borisova, G., Brockman, P., Salas, J. M., \& Zagorchev, A. (2012). Government ownership and corporate governance: Evidence from the EU. Journal of Banking and Finance, 36(11), 2917-2934. https://doi.org/10.1016/j.jbankfin.2012.01.008 
Borisova, G., Fotak, V., Holland, K., \& Megginson, W. (2015). Government ownership and the cost of debt: Evidence from government investments in publicly traded firms. Journal of Financial Economics, 118(1), 168-191. https://doi.org/10.1016/j.jfineco.2015.06.011

Boubakri, N., Ghoul, S. E., Guedhami, O., \& Megginson, W. L. (2018). The market value of government ownership. Journal of Corporate Finance, 50, 44-65. https://doi.org/10.1016/j.jcorpfin.2017.12.026

Brown, L. D., \& Caylor, M. L. (2004). Corporate governance and firm performance. University of Georgia, School of Accountancy, Atlanta. Retrieved from http://www.trustenablement.com/local/GSU_ISS_Study.pdf

Byrd, J. W. (2010). Financial policies and the agency costs of free cash flow: Evidence from the oil industry. International Review of Accounting, Banking and Finance, 2(2), 23-50. https://doi.org/10.2139/ssrn.1664654

Calabrò, A., \& Torchia, M. (2011). Conflicts of interest and governance mechanisms in Italian local public utilities. International Journal of Public Administration, 34(7), 447-460. https://doi.org/10.2139/ssrn.1861456

Chen, R., Ghoul, S. E., Guedhami, O., Kwok, C. C.Y, \& Nash, R. C. (2018a). State ownership and trade credit [Working Paper]. Social Science Research Network, Rochester, NY. Retrieved from https://ssrn.com/abstract=3103467

Chen, R., Ghoul, S. E., Guedhami, O., \& Nash, R. C. (2018b). State ownership and corporate cash holdings. Journal of Financial and Quantitative Analysis, 53(5), 2293-2334. https://doi.org/10.1017/S0022109018000236

Christensen, T., \& Lægreid, P. (2014). Performance and accountability - A theoretical discussion and an empirical assessment. Public Organization Review, 15(2), 207-225. https://doi.org/10.1007/s11115-013-0267-2

Coles, J. L., Daniel, N. D., \& Naveen, L. (2014). Co-opted boards. The Review of Financial Studies, 27(6), 1751-1796. https://doi.org/10.1093/rfs/hhu011

Cuervo-Cazurra, A., \& Dau, L. A. (2009). Promarket reforms and firm profitability in developing countries. Academy of Management Journal, 52(6), 1348-1368. https://doi.org/10.5465/amj.2009.47085192

Duchin, R., Matsusaka, J. G., \& Ozbas, O. (2010). When are outside directors effective? Journal of Financial Economics, 96(2), 195-214. https://doi.org/10.1016/j.jfineco.2009.12.004

Elkelish, W. (2018). Corporate governance risk and the agency problem. Corporate Governance: The International Journal of Business in Society, 18(2), 254-269. https://doi.org/10.1108/CG-082017-0195

Estrin, S., \& Pérotin, V. (1991). Does ownership always matter? International Journal of Industrial Organization, 9(1), 55-72. https://doi.org/10.1016/0167-7187(91)90005-6

Fama, E., \& Jensen, M. C. (1983). Separation of ownership and control. The Journal of Law and Economics, 26(2), 301-325. https://doi.org/10.1086/467037

Gilje, E., \& Taillard. J. (2016). Do private firms invest differently than public firms? Taking cues from the natural gas industry. Journal of Finance, 71(4), 1733-1778. https://doi.org/10.1111/jofi.12417

Gompers, P. A., Ishii, J. L., \& Metrick, A. (2003). Corporate governance and equity prices. The Quarterly Journal of Economics, 118(1), 107-156. https://doi.org/10.1162/00335530360535162 
Grossi, G., Papenfuß, U., \& Tremblay, M.-S. (2015). Corporate governance and accountability of stateowned enterprises: Relevance for science and society and interdisciplinary research perspectives. International Journal of Public Sector Management, 28(4/5), 274-285. https://doi.org/10.1108/JJPSM-09-2015-0166

Henry, D. (2010). Agency costs, ownership structure and corporate governance compliance: A private contracting perspective. Pacific-Basin Finance Journal, 18(1), 24-46. https://doi.org/10.1016/j.pacfin.2009.05.004

Jacobs, E. A. (1986). The agency cost of corporate control: The petroleum industry [Working Paper]. Massachusetts Institute of Technology, Cambridge, MA, EUA.

Jensen, M. C. (1986). Agency costs of free cash flow, corporate finance, and takeovers. The American Economic Review, 76(2), 323-329.

Jensen, M. C., \& Meckling, W. H. (1976). Theory of the firm: Managerial behavior, agency costs and ownership structure. Journal of Financial Economics, 3(4), 305-360. https://doi.org/10.1016/0304-405X(76)90026-X

La Porta, R., Lopez-de-Silanes, F., \& Shleifer, A. (2002). Government ownership of banks. The Journal of Finance, 57(1), 265-301. https://doi.org/10.1111/1540-6261.00422

Lima, S. H. O., Oliveira, F. D., Cabral, A. C. A., Santos, S. M. D., \& Pessoa, M. N. M. (2015). Governança corporativa e desempenho econômico: Uma análise dos indicadores de desempenho entre os três níveis do mercado diferenciado da BM\&FBovespa. Revista de Gestão, 22(2), 187204. https://doi.org/10.5700/rege558

Liu, C., Uchida, K., \& Yang, Y. (2012). Corporate governance and firm value during the global financial crisis: Evidence from China. International Review of Financial Analysis, 21, 70-80. https://doi.org/10.1016/j.irfa.2011.11.002

Lynn, L. E., Heinrich, C. J., \& Hill, C. J. (2000). Studying governance and public management: Challenges and prospects. Journal of Public Administration Research and Theory, 10(2), 233 261. https://doi.org/10.1093/oxfordjournals.jpart.a024269

Mcknight, P. J., \& Weir, C. (2009). Agency costs, corporate governance mechanisms and ownership structure in large UK publicly quoted companies: A panel data analysis. The Quarterly Review of Economics and Finance, 49(2), 139-158. https://doi.org/10.1016/j.qref.2007.09.008

Morck, R., Shleifer, A., \& Vishny, R. W. (1988). Management ownership and market valuation: An empirical analysis. Journal of Financial Economics, 20(1), 293-315. https://doi.org/10.1016/0304-405X(88)90048-7

Nheri, O. (2014). Economic reforms, corporate governance and privatization method as determinants in performance changes of new privatized firms: The case of MENA countries. Journal of Management \& Governance, 18(1), 95-127. https://doi.org/10.1007/s10997-012-9222-9

Owusu, A., \& Weir, C. (2018). Agency costs, ownership structure and corporate governance mechanisms in Ghana. International Journal of Accounting, Auditing and Performance Evaluation, 14(1), 63-84. https://doi.org/10.1504/IJAAPE.2018.089414

Peda, P., Grossi, G., \& Liik, M. (2013). Do ownership and size affect the performance of water utilities? Evidence from Estonian municipalities. Journal of Management \& Governance, 17(2), 237-259. https://doi.org/10.1007/s10997-011-9173-6

Rossi, F., Barth, J. R., \& Cebula, R. J. (2018). Do shareholder coalitions affect agency costs? Evidence from Italian-listed companies. Research in International Business and Finance, 46, 181-200. https://doi.org/10.1016/j.ribaf.2018.02.002 
Shleifer, A. (1998). State versus private ownership. Journal of Economic Perspectives, 12(4), 133-150. https://doi.org/10.1257/jep.12.4.133

Shleifer, A., \& Vishny, R. W. (1986). Large shareholders and corporate control. Journal of Political Economy, 94(3), 461-488.

Shleifer, A., \& Vishny, R. W. (1994). Politicians and firms. The Quarterly Journal of Economics, 109(4), 995-1025. https://doi.org/10.2307/2118354

Shleifer, A., \& Vishny, R. W. (1997). A survey of corporate governance. The Journal of Finance, 52(2), 737-783. https://doi.org/10.1111/j.1540-6261.1997.tb04820.x

Silveira, A. D. M., Barros, L. A. B. C., \& Famá, R. (2003). Estrutura de governança e valor das companhias abertas brasileira. Revista de Administração de Empresas, 43(3), 50-64. http://doi.org/10.1590/S0034-75902003000300005

Singh, M., \& Davidson, W. N. (2003). Agency costs, ownership structure and corporate governance mechanisms. Journal of Banking \& Finance, 27(5), 793-816. https://doi.org/10.1016/S03784266(01)00260-6

Ting, I. W. K., \& Lean, H. H. (2015). Does government ownership matter? Comparative study between Glcs and Nglcs in Malaysia. The Singapore Economic Review, 60(2), 1550019-1550041. https://doi.org/10.1142/S0217590815500198

Yermack, D. (1996). Higher market valuation of companies with a small board of directors. Journal of Financial Economics, 40(2), 185-211. https://doi.org/10.1016/0304-405X(95)00844-5

\author{
Autores \\ Rafael Pessoa Delgado \\ Av Presidente Wilson 118, 20030-020, Rio de Janeiro, RJ, Brasil \\ E-mail: rp_delgado@hotmail.com \\ Claudio Henrique da Silveira Barbedo \\ Av Presidente Wilson 118, 20030-020, Rio de Janeiro, RJ, Brasil \\ E-mail: claudio.barbedo@ibmec.edu.br
}

\title{
Contribuições
}

$1^{\circ}$ autor: Definição da questão teórica; desenho da estratégia metodológica; coleta e análise dos dados; elaboração do texto e; revisão final.

$2^{\circ}$ autor: Definição da questão de pesquisa; construção da fundamentação teórica; desenho da estratégia metodológica e; revisão final.

\section{Financiamento}

Os autores declaram que não há existência de apoio financeiro para a pesquisa neste artigo.

\section{Conflito de Interesses}

Os autores declaram que não há conflito de interesses.

\section{Verificação de Plágio}

A RAC mantém a prática de submeter todos os documentos aprovados para publicação à verificação de plágio, mediante o emprego de ferramentas específicas, e.g.: iThenticate.

\section{Material Suplementar}

Os autores optaram por não compartilhar a sua base de dados, e afirmam que o fazem tendo em vista que os dados foram retirados do sistema Bloomberg e se referem a bases de dados de empresas de vários países. A Bloomberg é uma plataforma paga. Para quem tem acesso ao sistema, os dados utilizados no trabalho estão disponíveis e é permitido/possível replicar a experiência. 